\title{
印尼建国大学中文系华文教育现状 \\ CHINESE TEACHING IN CHINESE DEPARTMENT OF BINUS UNIVERSITY
}

\author{
Andyni Khosasih \\ Chinese Department, Faculty of Languange and Culture, Binus University \\ Jl. Kemanggisan Ilir III No. 45, Kemanggisan/ Palmerah, Jakarta Barat 11480
}

\begin{abstract}
内容提要
印尼建国大学 (简称建大) 是印尼著名的大学之一, 成立于 1974 年, 位于雅加达西部。建国大学 中文系建立于 2002 年。目前共有 419 名学生、28 位教师。学生与教师来自不同的背景。师生不同的背 景启发笔者分析印尼建国大学华文教育现状 (学生、教师、使用教材、学校制度) 和解决方法, 使用的 研究方法是现场调查。通过分析笔者得出结论：一、建大中文系学生 (华裔和本地学生) 在听、说、 读、写方面都面临同样的困难; 二、建大目前的教师队伍还不太理想因为学士学位的教师数字高于硕士 学位的教师; 三、华裔学生的中文水平比本地学生好; 四、建大中文系所用的教材不完全适合在读中文 的中文系学生; 五、建大教学管理制度已良好。
\end{abstract}

关键词: 印尼建国大学、中文系、华文教育、现状

\begin{abstract}
ABSTACT
Binus University, established in 1974 and located in West Jakarta, is one of famous universities in Indonesia. This university has some literature departments including Chinese literature department which was started in 2002. At this moment, this department has 419 students and 28 lecturers who have different background. The difference of the students and lecturers' point of view becomes one the backgrounds of this paper. The others are text books used, campus rules and alternative solution toward the problem faced. The method used in this research is direct observation. From the data taken and analyzed, it can be concluded: (1) Chinese department students, either Chinese descendant or not, has problems in learning Chinese, (2) The number of lecturers of Bachelor graduates is more than the master ones, (3) The Chinese language mastery of Chinese descendant students is better than non Chinese descendant ones, (4) The text books used are not all suitable for Chinese department student, and (5) The quality control system of Chinese teaching is good.
\end{abstract}

Keywords: Binus University, Chinese department, Chinese teaching, recent condition 


\section{前言}

汉语现在成为国际交流语言之一。随着汉语热, 全世界学习汉语的学者越来越多, 印尼理 所当然也不例外, 尤其是 2000 年后, 印尼公民能自由地学习汉语。男女老幼都在学习汉语。 这些学者一部分在正规学校学习汉语, 另一部份在非正规学校学习。因为许多人在学习汉语的 缘故, 所以私人补习班日益增多。印尼的大学也逐渐成立中文系。目前雅加达已有 8 所大学开 办中文系, 有的是大专, 有的是本科专业。不管大专或本科专业, 在教学或发展中都遇到困 难。因此，笔者选择 “印尼建国大学中文系华文教育现状” 作为论文题目。目的为探讨建国大 学华文教育的现状及从所面临的困难中找出解决方。

\section{印尼建国大学中文系华文教育现状}

\section{一、印尼华文教育现状}

印尼华文教育办学形式分成四种:

（一）、家教式的的补习

据雅加达华文协调机构估计; 全印尼至少有 3000 名华文教师从事华语文家教, 多为 老华校的学生。这些年过半百的华文教师绝大多数没有大专或示范学历, 很多甚至初中 都未毕业, 没有学过拼音或语音, 更没有学过教学理论或教学法。

（二）、补习班或补习学校

补习班或补习学校都有华人社团或宗教团体支持, 财力、人力比较充裕。教学形式 和教学规划都比较有系统。师资也较强, 至少有一二名具有本科学士的华文教师。

\section{（三）、正规中小学及幼稚园}

印尼从事华语教学的正规中小学及幼稚园大致可分成四类：是教会办的、是华人办 的学校、市国际学校、是台湾学校。华文教育在这些学校的地位并不同, 有的认真教 学, 有的仅仅是防止学生流失, 顺应市场变化而作的权宜之计。

（四）、高等院校的华文教育

高等院校一般以中国高等院校现行的汉语专业主要课程为基础, 加上印尼高教司规 定的公共基础课。实施学分制, 学习年限专科三年、本科四年。目前, 毕业论文还允许 用印尼文获中文写, 但鼓励准毕业生用中文写论文。一般高等院校与中国高校合作, 实 施 2+2 或 3+1 双联课程。（中原大学应用华语文学系, 2006）

\section{二、印尼建国大学华文教育现状}

(一)、学生

随着中国的发展, 目前在印尼有成千上万的人在学习汉语。这些学者不仅在补习班 或在家里学习汉语, 而且在学校也上中文课。虽然不都学校把中文列入为必修课, 但一 部分高中生上大学时选择了中文系。在雅加达, 设有中文系的大学共有 8 所, 其中是印 尼建国大学（Universitas Bina Nusantara）、印尼大学（Universitas Indonesia）、 新雅学院（Xinya College）、印尼基督教大学（Universitas Kristen Indonesia）、 
圣母大学 (Universitas Bunda Mulia) 、阿尔·哈沙（回教）大学 (Universitas A1 Azhar Indonesia) 、达尔玛勃沙塔大学 (Universitas Darma Persada) 与国民大学 (Universitas Nasiona1)。印尼建国大学目前共有 419 学生。学生来自不同的背景。大多 数学生来自雅加达。建大学生可分成两类:

1. 土生土长 (本地) 学生

土生土长学生绝大多数来自雅加达、茂物与勿加泗。他们基本上都没有汉语基础。可说 是从零起点开始学习汉语的。因没有汉语基础的缘故, 所以在学习过程中不少学生遇到 困难。少数学生在高中时学过汉语, 可这些学生都不掌握所学过的东西。主要原因是教 师素质不高。许多在国立学校任教的中文教师无法讲一口流利的汉语。

下面是土生土长学生学习汉语时面临的困难:

(1) 听力

听力对一个学习外语或非汉语母语的学者来说经常成为最大的障碍。学生常常听 不懂教师在课堂上所教的内容或课外话题。听不懂的主要因素是词汇量不够、缺 乏语言环境。学生词汇量有限的原因他们在课外极少复习, 有的甚至完全没有复 习, 期中或期末考试时才复习。因此学习成了应付考试的工具。若学生都采取临 时抱佛脚的学习方法, 理所当然掌握不好汉语。

缺乏语言环境是因为学生只有在学校时才有机会讲汉语。除了在学校以外, 基本 上没有机会能用汉语与周围的人沟通。尽管如此, 还是有很多学生在学校是比较 喜欢用印尼语作为交际工具。这样学生无法提高听力能力。

(2) 口语

本地学生大多数口语能力不好。主要因素是家长、亲朋好友很少掌握汉语。这导 致他们口语讲得不太流利。可说, 缺乏语言环境成为本地学生口语能力不好的因 素。本地学生大多数进入中文系之前都没有汉语基础。因此在学习上（如：汉语 拼音、生词）常常遇到困难。另外, 懒惰是本地学生口语能力不好其中的一个重 要因素。其他原因是学生在公共场合不敢讲汉语。

(3) 阅读

在阅读方面, 不少本地学生阅读能力非常差。主要原因是词汇量有限。因此, 他 们经常看不懂课文内容。少部分学生不掌握阅读技巧。另外, 极少阅读中文书造 成学生阅读能力差的其中一个因素。

(4) 汉字

汉字是外国人学习汉语时不易掌握的知识。印尼使用拉丁字母, 所以掌握汉字对 学生来说是一件不容易的事情。若要掌握汉字得下不少功夫。建大学生难以掌握 汉字是因为他们不常练写汉字。这导致学生难以记住所学过的汉字。

2. 华裔学生

华裔学生大多数也是来自雅加达。他们大都已有汉语基础。有的自幼就开始学习中文, 有的是在补习班或在学校学的。少部分是父母教的。除了来自雅加达以外, 少数学生来 自邦加、巨港、坤甸、巴干西阿比阿比、占碑。外地学生都有汉语基础。他们的中文水 平较好。华裔学生虽然大都有汉语基础，可在学习上还是遇到困难。

(1) 听力

听力对华裔学生来说也是他们学习汉语中遇到的障碍。与本地学生对比, 华裔学 生听力能力较强。这是因为亲属会讲汉语、自小父母就让他们补习汉语或看中文 电影。华裔学生听力能力差的原因基本上与本地学生一样。

(2) 口语

华裔学生比本地学生口语能力较强。主要因素是大多数华裔学生会讲方言, 有的 甚至在家里讲中文。若掌握中国的一种方言的话, 就比较容易掌握汉语。例如: 闽南话、客家话、广东话。华裔学生掌握中国方言, 所以比较容易吸收教师所教 
的内容。有关为何华裔学生口语不流利的缘故, 可说与本地学生一样。少数学生 汉语水平考试得六、七级 (HSK 旧版考试) 可中文说得不流利, 原因是不敢在公共 场合讲中文、习惯使用印尼语作为交际工具。

(3) 阅读

本地大多学生不喜欢阅读中文书或中文教材, 华裔学生也不例外。他们比较喜 欢阅读日韩书或看日韩电影。这导致学生的阅读能力较差。另外, 不掌握阅读 技巧成为学生掌握阅读的障碍。学生不掌握阅读技巧是因为在课堂上不听课、 不接受教师所传授的教学技巧。

(4) 汉字

与听力、口语、阅读一样, 华裔学生在掌握汉字方面也比本地学生强。汉子对 大多数学生来说不陌生。虽然进入中文系之前不会写汉字, 但在家里、亲戚 家、或在社会上基本上接触过懂中文的人。这是与本地学生的区别。本地学生 大都进入中文系之后, 才认识汉子。尽管如此, 华裔学生掌握汉字时面临的困 难与本地学生一样。

从以上分析, 得知华裔学生中文水平比本地学生好, 可同样在学习汉语时遇到的障 碍是一样的。华裔学生与本地学生中文水平不一致, 所以教师在教学中有时难以按 照已定好的教学大纲传授知识。另外, 由于印尼人民大都不会讲汉语, 因此不少学 生进入中文系时没有中文基础。在读汉语的学生也缺乏良好的语言环境。这主要成 为学生掌握汉语时最大的障碍。

（二）、教师

教师在教学时成了一个重要因素。目前师资成为印尼华文教育的一个不易解决的难 题。印尼华文教育现在缺乏良好的师资。中文好的大都是长辈（以前都念华校），而年 轻人的水平稍微差一点儿。虽然长辈们中文水平比年轻人好, 可发音和声调比年轻人 差。

建大是一个年轻的华文教师队伍。目前共有二十八位教师, 拥有硕士学位的占 $25 \%, 21.5 \%$ 在读研究生, 学士学位占 $53.5 \%$ 。从二十八位教师当中, 只有七位是全职教 师, 其余的是专职教师。目前建大逐渐取消专职教师模式, 而走向全职教师模式, 主要 目的是为了提高教师素质。

建大教师可分成两类:

1. 本地教师。

建国大学本地教师本身可分成两类：国内毕业与国外毕业的华文教师（留学中国或 台湾）。国内毕业的教师主要毕业于建国大学、印尼大学和达尔玛勃沙塔大学。国 内毕业的教师在建大中文系占少数。这些教师一般参加过国内或国外（中国、台 湾) 的师资培训。国外毕业的教师主要毕业于华裔大学。除了华裔大学以外, 少数 教师毕业于厦门大学、暨南大学、台湾大学、台湾师范大学等高等院校。目前建大 本地教师的汉语水平考试成绩已达到高等水平。少数教师的学历背景是非中文系或 汉语言专业。尽管如此, 他们都是从事华文教育（留学中国或台湾）或专业人士。 这些教师的中文水平非常好。

2. 中国教师

目前建大拥有三位中国教师, 其中两位是全职教师。他们除了上课以外, 协助系上 的一些工作, 如负责建大学生的华文报、科研、辅导学生等。中国教师不参与行政 工作。基本上中国教师任教高年级的学生, 其中是古代汉语、现代汉语、现当代文 
学、中级语法等科目。有时中国教师任教初级口语和初级写作。中国教师的存在加 强了建大教师队伍。

中国教师与本地教师的关系十分融洽, 彼此可互相学习。目前从二十八位教师中, 只有四位教师拥有教师职称, 有的还在申请, 有的现在无法向印尼教育部申请是因 为没有做过科研。此问题不只是建大所面临的困难，而是整个印尼华文教育现在难 以解决的问题。

\section{（三）、使用教材}

印尼华文教育到目前为止缺乏适合本地学生的教材, 尤其是中文系的学生。现在印 尼没有教师编写中文系学生的教材。因此高校都使用中国教师编写的教材。最多使用北 京语言大学出版社和北京大学出版社出版的教材。这导致一部分学生难以掌握教科书里 的内容因为教科书里的背景是中国的社会现象或文化遗产，如《汉语教程》中提到的四 合院。在中国, 谁都知道所谓的四合院, 可印尼学生完全没有这个概念。这样教师得下 更多的功夫让学生理解所谓的四合院。

建大中文系目前使用几所出版社出版的教材, 可还是以北京语言大学出版社和北京 大学出版社为主。使用几所出版社的教材导致教学中除了双平线, 如初级语法可使用 《汉语教程》北京语言大学出版社出版的教材, 而初级口语使用《初级汉语口语》北京 大学出版深出版的教材。这样, 在初级语法和初级口语课教科书里的内容没有连接性。 因此增加了学生的负担, 影响了教学效率。

\section{（四）、教学管理制度}

印尼教育部规定 2014 年时, 大学教师至少必须拥有硕士学位。目前印尼教育部还允 许学士学位毕业生在大学任教, 原因有些院系难以找到硕士毕业生, 如: 中文系、日文 系。建大目前还录取学士学位的教师, 原因是在印尼现在拥有硕士学位而中文流利的教 师并不多。尽管如此, 从 2012 开始只有拥有硕士学位以上学历的教师才有资格任教。另 外, 为提高教学目的 (以学生为中心) 和现代化接轨, 建大实行了网络教学。每个学生 除了在课堂上与教师交流, 还可以通过 Binusmaya 和教师进行交流。Binusmaya 是建大 创造的网络教学系统。通过 Binusmaya, 师生之间的交流可在任何地方、任何时间。因 此校方要求所有教师都得熟练电脑。若电脑技术不好, 教师必须参加学校举办的电脑培 训。除了以上的学校制度, 学校每学期对每位教师给予评价。最高分数为 4.00 , 每位教 师的分数至少得达到 3.00 。若教师的分数低于 3.00 , 教师得参加学校制定的培训, 如: 教学法、课堂管理、如何有效地与学生沟通等培训项目。这些培训的目的是提高教师素 质和教学质量。

三、 解决方法

下面是建大中文系可参考的解决方法:

（一）、为提高学生的素质和中文水平, 中文系必须培养学生的独立性、创造学生随时 可讲中文的机会，如：设立汉语角、校内中文比赛。

(二) 、为提高教学效率, 首先得提高教师素质, 其中可通过培养人才、聘请至少硕士 学位中文系专业人才。

（三）、与中国的大学合作, 如: 夏令营、中文培训、交换师生甚至长期的合作项目 (例如: 奖学金、互认学分等)。 
（四）、与其它拥有中文系的大学合作编写适合印尼中文系大学生的教材。

（五）、保持学校已定的制度, 扩大 Binusmaya 在教学中的功能。

\section{结论}

从以上分析，笔者得出以下结论：

一、建大中文系学生（华裔和本地学生）在听、说、读、写方面都面临同样的困难。

二、建大目前的教师队伍还不太理想因为学士学位的教师数字高于硕士学位的教师。

三、华裔学生的中文水平比本地学生好。

四、建大中文系所用的教材不完全适合在读中文的中文系学生。

五、建大教学管理制度已良好。

\section{参考文献}

中原大学应用华语文学系・印尼华文教育语教学【M】・中原大学应用华语文学系出版, 2006 黄昆章・印尼华侨华人史 1950 至 2004 年【M】・广东高等教育出版社，2005 年

http://www.chinaqw.com/node2/node2796/node2797/node2805/userobject6ai235288.html

http://www.cic.mofcom.gov.cn/ciweb/cic/info/Article.jsp?a no=79692\&col_no=464

http://www.gd.xinhuanet.com/newscenter/ztbd/2008-05/18/content 13291397.htm

http://www.jiaoshi.com.cn/main/news 13809.html

http://hqhr.jnu.edu.cn/article.asp?newsid=9022

http://news.163.com/05/1230/17/2683JK3000011EQ3.html

http://news.sina.com.cn/c/2009-07-17/155115970643s.shtml

http://www.pianohome.cn/n4642c342.shtml 